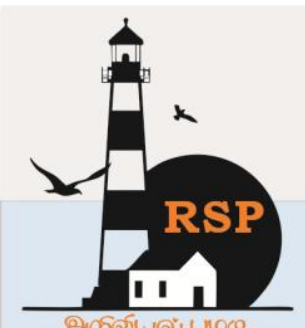

INTERNATIONAL RESEARCH JOURNAL ON ADVANCED SCIENCE HUB

ISSN : $2582-4376$
Open Access

RSP SCIENCE HUB

(The Hub of Research Ideas)

Available online at www.rspsciencehub.com

Special Issue of Second International Conference on Advancements in Research and Development (ICARD 2021)

\title{
ATM Banking System
}

Arthi $S^{1}$,Dinesh $R^{2}$,Hemalatha $P^{3}$,Sivaranjani $V^{4}$,Sangeetha $K^{5}$

${ }^{1,2,3}$ UG Scholar, Department of Computer Science and Engineering, SNS College of Technology, Coimbatore, India.

${ }^{4,5}$ Assistant Professor, Department of Computer Science and Engineering, SNS College of Technology, Coimbatore, India.

arthikumar2000@gmail.com ${ }^{1}$,dineshrangasamy@gmail.com ${ }^{2}$, phemalatha514@gmail.com ${ }^{3}$, sivu1990@gmail.com ${ }^{4}$,Sangithaprakash@gmail.com ${ }^{5}$

\begin{abstract}
In financial framework, various branches are available and these are associated with the principle branch. Thus, a similar bank is situated at various areas for giving similar sort of banking administrations. Internet Banking is an electronic broadcast communications gadget that gives the clients of a monetary organization with admittance to monetary exchanges in a public space without the requirement for a human agent or bank employee The manual strategy for dealing with these banks from one area is troublesome, yet it very well may be effectively finished with an ATM programming application like this. With this ATM Banking System programming, different errands should be possible by a regular Bank Management Application, for example, adding client subtleties, seeing client money withdrawal/store subtleties, oversee banking accounts, creating pin, producing endless supply of money, and some more. The general financial strategy has gotten a lot simpler, agreeable and got also with ATM (Automated Teller Machine). ATM possesses saved clients energy for pulling out balance, checking late exchanges and checking bank balance from any area. With the proposed ATM Banking System, bank the executives is simpler with a more productive stage for overseeing client subtleties, dealing with their record and recording their exchange history. This venture can assist understudies with understanding the activities that are associated with planning ATM programming. The proposed framework is acceptable and it has a base highlights, however further improvements should be possible by adding new modules, highlights and sub-frameworks into this task.
\end{abstract}

Keywords: ATM Banking System, Internet Banking, Security, Encryption.

\section{Introduction}

Banking innovation is growing quickly to such an extent that it is thoroughly changing the dealings of banking exercises. These advancements are taking financial exercises to another level. Perhaps the main approach in financial innovation that has left and is leaving both positive and negative effects on exchanges and different exercises acted in banks is "Computerized Teller Machine". With an Automated Teller Machine, a client can perform different exercises like withdrawal of money, moving cash, covering telephone and power bills past true hours and without connecting with any staff part. Computerized Teller Machine gives a proficient and quick route to 
the clients for getting to their ledgers and for making monetary exchanges. Individuals knew the estimation of Automated Teller Machines like around 40 years prior when they understood that it's a quick method to execute cash without entering the bank and remaining in a line, trusting that the turn will come and afterward to be served. Before the presentation of the robotized Teller Machines, it was normally seen a line of individuals lining up external the banks before the launch of the banks to gather some money and banks were frequently extremely occupied because of an enormous number of individuals pulling out cash. Mechanized Teller beat this issue as their utilization isn't restricted to bank opening times yet they work all day, every day without connecting with any staff of the bank. They never get closed down however just when they are out of money or they have quit working.

Robotized Teller Machine is essentially an electronic machine that is intended to give money to the clients without the cooperation of any human. Our project named as "ATM Banking System" is tied in with bringing the banks underneath our thumb. The general motivation behind this venture is to assess and investigations the necessity of the client, plan and execute the framework, testing the usefulness and keep up the product of an ATM part of a bigger ATM network project, predictable with the prerequisite detail. ATM (Automated teller machine) utilizes programming application for performing banking tasks. This venture is called as ATM Banking Project which is valuable for adding client subtleties, overseeing ledgers, see client money withdrawal, produce pin, create receipt Etc. At present financial interaction is getting simpler and client are saving time for checking balance, pull out cash from any area utilizing ATM machines, check late exchanges and so forth In building up this engineering programming and equipment applications are planned. In this venture we planned as ATM banking framework project for understanding activities that are associated with ATM programming and added numerous highlights that are available in present ATM programming.

\subsection{Objective}

Our principle objective is to accelerate the exchanges done by the clients. No manual exchange required by and large. The subsequent goal is to save the time which is vital nowadays. It additionally fulfils the necessities of the current framework in an undeniable way. The primary motivation behind this venture is to help people in general in realizing their place subtleties and getting their issues settled in online without going to the official routinely until the issue is addressed. By this framework people in general can save his time. Simultaneously, if the message that will be covered up were scrambled, the degree of security would be raised to a serious good level. Presently, regardless of whether the secret message were to be found the individual attempting to get the message would just have the option to lay his hands on the scrambled message with no chance to get of having the option to decode it.

\section{Literature Survey}

Computerized teller machine banking has become a huge channel for banking items and administrations behind branch banking in Malawi and banks keep on putting resources into new and effective innovations that can deal with more capacities that incorporate money storing to pull in more clients and accomplish consumer loyalty with the banks. 353 respondents took an interest in this investigation to survey the effect of Automated teller machine banking execution on consumer loyalty with banks.Information covering up in sound signs is particularly difficult on the grounds that the Human Auditory System (HAS) works over a wide powerful reach. The HAS sees over a scope of force more prominent than one billion to one and a scope of frequencies more noteworthy than thousand to one. The annoyances in a sound document can be distinguished however low as one section in ten million which seems to be $80 \mathrm{~dB}$ beneath surrounding. The effect of robotized administration quality on bank monetary execution and the interceding part of client maintenance have gotten little consideration, as researchers have zeroed in on issues of convenience and estimation. This examination starts by showing the effect of innovation in transit banks lead business and continues to talk 


\section{www.rspsciencehub.com}

about computerized administration quality definitions and the expected impact of robotized administration quality on maintenance and monetary execution. [1-6]

\section{Audio File Format}

Organized sound information alludes to sound in any of various standard organizations. The Java Sound API recognizes information configurations and record designs. An information design reveals to you how to decipher a progression of bytes of "crude"

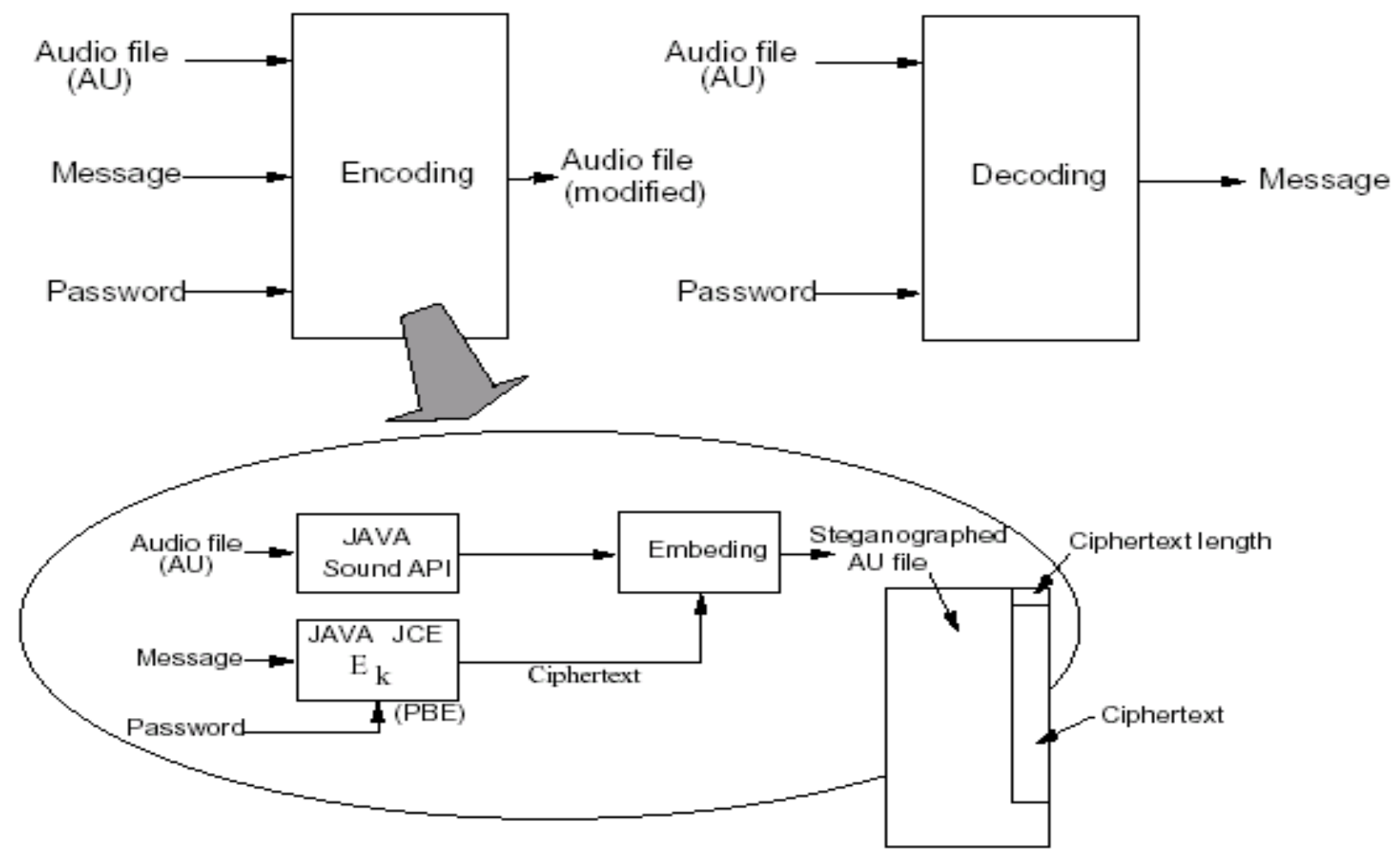

Fig.1. Data Hiding in Audio Files

\section{Proposed System}

The point of proposed framework is to build up an arrangement of improved offices. The proposed framework can conquer every one of the limits of the current framework. The framework gives appropriate security and lessens the manual work. The proposed framework utilizes Audio record as a transporter medium which add another progression in security. The target of the recently proposed framework is to make a framework that makes it extremely hard for an adversary to recognize the presence of a mysterious message by encoding it in the transporter medium as a component of some mysterious key and that stays as the upside of this framework. inspected sound information, for example, tests that have been caught from the amplifier input. You may have to know, for instance the number of pieces comprise one example (the portrayal of the most limited moment of sound), and comparably you may have to realize the sound's example rate (digger quick the examples should follow each other). When setting up for playback or catch, you determine the information organization of the sound you are catching or playing. 
issues are likewise considered and deduced in our discoveries. This proposition covering security and specialized issues with ATM banking framework.

\section{References}

[1].Charles Mwatsika: Impact of ATM Banking Performance on Customer Satisfaction with the Bank in Malawi

[2].Aldlaigan, A., and Buttle, A. (2002). SYSTRA-SQ: a new measure of banks service quality. International Journal of Service Industry Management. 13(4), pp. 362-381.

[3].Al-Hawari, M. and Ward, T. (2006). The impact of automated service quality on financial performance and the mediating role of customer retention. Journal of Financial Service Marketing. 10(3), pp. 228-43.

[4]. Andaleeb, S. S. and Basu, A. K. (1994). Technical complexity and consumer knowledge as moderators of service quality evaluations in the automobile service industry. Journal of Retailing Vol. 70(4) pp367-379.

[5].Anderson, E., \& Sullivan, M. (1993). The antecedents and consequences of customer's satisfaction for firms. Marketing Science, 12(2), 125-143.

[6].Anderson, E. W. and Fornell, C. (1994). A customer satisfaction research prospectus. Services marketing: new directions in theory and practice. Thousand Oaks, CA: Sage Publications, pp. 241-68. 